\title{
Not just pain and morning stiffness duration in the daily experience of patients with polymyalgia rheumatica. Does the rheumatologist listen to all patient-reported outcomes?
}

\author{
Ciro Manzo ID , Alberto Castagna2 ID $^{2}$ Betul Sargin ${ }^{3}$ ID \\ ${ }^{1}$ Azienda Sanitaria Locale Napoli 3 sud, Internal and Geriatric Medicine Department, Rheumatologic Outpatient Clinic Hospital \\ "Mariano Lauro", Sant'Agnello, Italy \\ ${ }^{2}$ Azienda Sanitaria Provinciale Catanzaro, Primary Care Department, Fragility Outpatient Clinic, Catanzaro, Italy \\ ${ }^{3}$ Department of Physical Medicine and Rehabilitation, Division of Rheumatology, Medical Faculty, Adnan Menderes University, Aydın, \\ Turkey
}

\begin{abstract}
Patient-reported outcomes (PROs) provide a means for patients to communicate with their care teams about their disease. Polymyalgia rheumatica (PMR) is considered to be one of the most common inflammatory rheumatic diseases in older adults. The Visual Analogue Scale (VAS) of pain is the only PRO assessed by the PMR activity score (PMR-AS), which is still the only validated score for monitoring disease activity in patients affected with PMR. Other PROs such as fatigue, sleep disturbances, depressive symptoms, and patient's perspective related to adverse effects of prednisolone are still unmet needs. This short communication suggests the gerontorheumatological outpatient clinic as an answer
\end{abstract}

Key words: polymyalgia rheumatica, patient-reported outcomes, gerontorheumatologist, activity score.

Polymyalgia rheumatica (PMR) is considered to be one of the most common inflammatory rheumatic diseases in older adults. The main symptoms in PMR patients are a sudden-onset bilateral pain in the shoulder and pelvic girdles, associated with morning stiffness lasting > $45 \mathrm{~min}$. In some patients, neck ache is also present.

Consequently, all self-care activities of daily living dependent on the shoulder and pelvic girdles are significantly restricted, including getting dressed, toileting, getting in and out of a bath, and turning over in bed. These disabling effects are so sudden that the patient remembers the exact day and hour when PMR started.

Low-dose glucocorticosteroids (GCS) are an effective treatment resulting in a striking improvement of symptoms. However, the rates and timing of improvement are not the same for all patients, and relapses are possible, especially during the first months of GC therapy $[1,2]$.
In 2005, Leeb and Bird [3] proposed a PMR activity score (PMR-AS) incorporating five variables: C-reactive protein (CRP) concentrations, patient's pain assessment, physician's global assessment, morning stiffness duration, and elevation of the upper limbs.

To date, the PMR-AS is the only validated score for monitoring disease activity in patients affected with PMR. Nevertheless, an international work group highlighted the important and missing variables as assessment of GC dose, hip functions and patient's global assessment [4].

In 2018, Devauchelle-Pensec et al. [5] described a modified version of Leeb and Bird's PMR-AS to apply in patients whose CRP concentrations are unavailable or uninterpretable. To date, these two activity scores are still poorly used in published literature, although they could be a way to speak a common language and have comparable data. 
Patient-reported outcomes (PROs) provide a means for patients to communicate with their care teams about their disease. In addition, PROs have been proven to add valuable and unique information on treatment efficacy and quality of life that is immediately relevant to the management of their disease activity [6-8].

The Visual Analogue Scale (VAS) of pain is the only PRO assessed by the PMR-AS. Moreover, morning stiffness duration is different from daily stiffness severity. Indeed, stiffness severity fluctuates throughout the day (and is not restricted to the morning), and it influences functional ability more than pain and morning stiffness duration [9].

Finally, as recently reported by some investigators, pain and stiffness can have different profiles over time [10]. Fatigue, sleep disturbances, depressive symptoms, and patient's perspective related to adverse effects of GCs $[11,12]$ are other relevant PROs.

The facts are that:

1) less than $10 \%$ of published studies measured fatigue or physical functions [13],

2) recently, an overall lack of robustness and accuracy emerged for diagnosis of depression and depressive symptoms in PMR patients, because rating scales were used in published literature rather than targeted clinical interviews and/or standardized diagnostic criteria [14],

3) the assessment of sleep disturbances in PMR patients is still anecdotal [15],

4) with regard to the assessment of patients' perspectives related to GC additional morbidity, there are very few studies about emotional and psychological consequences of GC therapy in PMR patients, despite their strong impact on the relationship between patient and rheumatologist [16-18],

5) although the management of rheumatologic disorders in elderly patients is often complicated by comorbidities and by an increased frequency of adverse drug reactions, these patients are not always systematically assessed for these variables [19].

Since 2014, the OMERACT-PMR special interest group published some articles on these topics, highlighting - for instance - that the instruments used to measure outcomes in some rheumatic patients are not always appropriate for PMR patients [12, 13, 20-23].

In particular, Owen et al. [20] pointed out that some questions proposed by the Health Assessment Questionnaires (HAQ) are not relevant in older patients, and that - therefore - the HAQ might not be an effective tool for measuring the physical functions in patients with PMR.

Other questionnaires such as the Functional Assessment of Chronic Illness Therapy (FACIT) - Fatigue questionnaire have been validated in some rheumatic diseases such as psoriatic arthritis but not in PMR [21].

On the other hand, sleep disturbances are often expressed by PMR patients but they are not included in a core domain set for PMR $[13,20]$. There is therefore a long way still to go.

The gerontorheumatological outpatient clinic differs from the non-gerontorheumatological outpatient clinic because it has a specific methodological instrument that is the multidimensional assessment, able to take into account - for instance - all the age-related psychological, social, and cultural issues, that are likely to have an impact on health status and patient's treatment [24-26].

All too little is being written about the absence in almost all the research groups of those who know the "older patients' language" and can identify all age-related health hazards.

The authors declare no conflict of interest.

\section{References}

1. Manzo C, Camellino D. Polymyalgia rheumatica: diagnostic and therapeutic issues of an apparently straightforward disease. Recenti Prog Med 2017; 108: 221-231, DOI: 10.1701/ 2695.27559 [Article in Italian].

2. Manzo C, Natale M, Traini E. Diagnosis of polymyalgia rheumatica in primary health care: favoring and confounding factors - a cohort study. Reumatologia 2018; 56: 131-139, DOI: 10.5114/reum.2018.76900.

3. Leeb BF, Bird HA. A disease activity score for polymyalgia rheumatic. Ann Rheum Dis 2004; 63: 1279-1283, DOI: 10.1136/ ard.2003.011379.

4. Dejaco C, Duftner C, Cimmino MA, et al. Definition of remission and relapse in polymyalgia rheumatica: data from a literature search compared with a Delphi-based expert consensus. Ann Rheum Dis 2011; 70: 447-453, DOI: 10.1136/ard.2010.133850.

5. Devauchelle-Pensec V, Saraux L, Berthelot JM, et al. Assessing polymyalgia rheumatica activity when C-reactive protein is unavailable or uninterpretable. Rheumatology (Oxford) 2018; 57, 666-670, DOI: 10.1093/rheumatology/kex477.

6. Shortell SM, Poon BY, Ramsay PP, et al A multilevel analysis of patient engagement and patient-reported outcomes in primary care practices of accountable care organizations. J Gen Intern Med 2017; 32: 640-647, DOI: 10.1007/s11606-016-3980-z.

7. Philpot LM, Barnes SA, Brown RM, et al. Barriers and benefits to the use of patient-reported outcome measures in routine clinical care: a qualitative study. Am J Med Qual 2018; 33: 359-364, DOI: 10.1177/1062860617745986.

8. de Wit MP, Berlo SE, Aanerud GJ, et al. European League Against Rheumatism recommendations for the inclusion of patient representatives in scientific projects. Ann Rheum Dis 2011; 70: 722-726, DOI: 10.1136/ard.2010.135129.

9. Mackie SL, Hughes R, Walsh M, et al. "An impediment to living life": why and how should we measure stiffness in polymyal- 
gia rheumatica? PLoS One 2015; 10: e0126758, DOI: 10.1371/ journal.pone.0126758.

10. Muller S, Whittle R, Hider SL, et al. Longitudinal clusters of pain and stiffness in polymyalgia rherheumatic-year results from the PMR Cohort Study. Rheumatology (Oxford) 2020; 59: 1906-1915, DOI: 10.1093/rheumatology/kez533.

11. Matteson EL, Maradit-Kremers H, Cimmino MA, et al. Patientreported outcomes in polymyalgia reumatica. J Rheumatol 2012; 39: 795-803, DOI: 10.3899/jrheum.110977.

12. Black RJ, Robson JC, Goodman SM, et al. A patient-reported outcome measure for effect of glucocorticoid therapy in adults with inflammatory diseases is needed: report from the OMERACT 2016 special interest group. J Rheumatol 2017; 44 1754-1758, DOI: 10.3899/jrheum.161083.

13. Mackie SL, Arat S, da Silva J, et al. Polymyalgia Rheumatica (PMR) special interest group at OMERACT 11: outcomes of importance for patients with PMR. J Rheumatol 2014; 41: 819-823, DOI: 10.3899/jrheum.131254.

14. Manzo C, Nizama-Via A, Milckert M, et al. Depression and depressive symptoms in patients with polymyalgia rheumatica: discussion points, grey areas and unmet needs emerging from a systematic review of published literature. Reumatologia 2020; 58: 381-389, DOI: 10.5114/reum.2020.102003.

15. Manzo C, Castagna A. Subjective sleep disturbances at the time of diagnosis in patients with polymyalgia rheumatica and in patients with seronegative elderly-onset rheumatoid arthritis. A pilot study. Reumatologia 2020; 58: 196-201, DOI 10.5114/reum.2020.98430.

16. Hoon E, Ruediger C, Gill TK, et al. A qualitative study of patient perspectives related to glucocorticoid therapy in polymyalgia rheumatica and giant cell arteritis. Open Access Rheumatol 2019; 11: 189-198, DOI: 10.2147/OARRR.S213964.

17. Manzo C, Serra-Mestres J, Castagna A, Isetta M. Behavioral, psychiatric, and cognitive adverse events in older persons treated with glucocorticoids. Medicines (Basel) 2018; 5: 82, DOI: $10.3390 /$ medicines5030082.
18. Twohig H, Mitchell C, Mallen C, et al. "I suddenly felt l'd aged": a qualitative study of patients experiences of polymyalgia rheumatica (PMR). Patient Educ Couns 2015; 98: 645-650, DOI: 10.1016/j.pec.2014.12.013.

19. Manzo C, Putignano S, Stisi S. Malattie reumatiche e paziente geriatrico: spunti operativi e qualche riflessione per un mondo che sta cambiando. G It Reumatol Clin 2016; 2: 15-27 [Article in Italian].

20. Owen CE, Yates M, Twohig H, et al. Toward a core outcome measurement set for Polymyalgia Rheumatica: report from the OMERACT 2018 special interest group. J Rheumatol 2019; 46: 1360-1364, DOI: 10.3899/jrheum.181050.

21. Duarte C, Ferreira RJ, Mackie SL, et al. Outcome measures in polymyalgia rheumatica: a systematic review. J Rheumatol 2015; 42: 2503-2511, DOI: 10.3899/jrheum.150515.

22. Yates M, Owen CE, Muller S, et al. Feasibility and face validity of outcome measures for use in future studies of polymyalgia rheumatica: an OMERACT study. J Rheumatol 2020; 47: 13791384, DOI: 10.3899/jrheum.190575.

23. Prior JA, Muller S, Helliwell T, et al. The association of pain and stiffness with fatigue in incident polymyalgia rheumatica: baseline results from the polymyalgia rheumatica cohort study. Prim Health Care Res Dev 2019; 20: e46, DOI: 10.1017/ S1463423619000082.

24. van Lankveld W, Franssen M, Stenger A. Gerontorheumatology: the challenge to meet health-care demands for the elderly with musculoskeletal conditions. Rheumatology (Oxford) 2005; 44: 419-422, DOI: 10.1093/rheumatology/keh555.

25. Manzo C. La polimialgia reumatica: cosa è utile sapere per il geriatra territoriale? Geriatria Extraospedaliera 2009; 7: 9-11 [Article in Italian].

26. Michet CJ Jr, Evans JM, Fleming KC, et al. Common rheumatologic diseases in elderly patients. Mayo Clin Proc 1995; 70: 1205-1214, DOI: 10.4065/70.12.1205. 